\title{
Purification and characterization of lactate dehydrogenase from Varanus liver
}

\author{
Masood H. Javed, ${ }^{1,3}$ Syed M. I. Azimuddin, ${ }^{2}$ \\ Abida N. Hussain, ${ }^{1}$ Asifa Ahmed $^{2}$ and \\ Mohammad Ishaq ${ }^{2}$ \\ 1 Department of Biochemistry, The Aga Khan University, \\ Karachi, Pakistan \\ 2 Department of Biochemistry, Karachi University, Karachi, Pakistan \\ 3 Corresponding author \\ Accepted 7 January 1997
}

Abbreviations: LDH, lactate dehydrogenase; AGE, Agarose gel electrophoresis; KPE, potassium phosphate buffer containing EDTA

\begin{abstract}
Lactate dehydrogenase was purified 21-fold from liver of Varanus bengalensis using colchicinesepharose column chromatography. The crude enzyme showed two isoenzymes (LDH-5 and LDH-4) by agarose gel electrophoresis (AGE). The purified enzyme showed a single band after SDS-PAGE corresponding to molecular mass of $35 \mathrm{kDa}$. The molecular mass of native enzyme was about 140 $\mathrm{kDa}$. The optimum $\mathrm{pH}$ for the forward reaction was 7.5 while that for the reverse reaction was $\mathrm{pH} 9.5$. The $\mathrm{K}_{\mathrm{m}}$ values for pyruvate, NADH, lactate and $\mathrm{NAD}^{+}$were $0.17 \pm 0.037,0.02 \pm 0.004,12.4 \pm 3.05$ and $0.38 \pm 0.032 \mathrm{mM}$, respectively. Pre-heating of enzyme showed that its $t_{50}$ was $40-50^{\circ} \mathrm{C}$. Oxalate and $n$-hexanediol were inhibitors for both forward and reverse reactions. Among divalent ions, $\mathrm{Cu}^{++}$ was shown to be more effective inhibitor for the forward reaction.
\end{abstract}

Keywords: LDH isoenzyme, liver, properties, purification, Varanus bengalensis

\section{Introduction}

Lactate dehydrogenase (L-lactate:NAD oxidoreductase, EC 1.1.1.27; $\mathrm{LDH}$ ) plays an important role in the regulation of anaerobic glycolysis through reoxidation of NADH (Everse and Kaplan, 1973; Javed et al., 1995). The structure of vertebrate $\mathrm{LDH}$ has been investigated by a number of investigators (Cahn et al., 1962; Everse and Kaplan, 1973; Li et al., 1989)) who have shown that it is a tetramer composed of two subunits, A (M or muscle or type-5) and $\mathrm{B}$ ( $\mathrm{H}$ or heart or type-1). The combinations of various forms of subunits produce five isoenzymes (Maekawa, 1988; Javed et al. 1995). These isoenzymes differ in various physicochemical, immunological and physiological properties (Everse and Kaplan, 1973; Maekawa, 1988; Javed and Waqar, 1993).

LDH isoenzymes are not formed by random subunits combinations, and differences in the proportions of subunit for isoenzymes in different tissues (organs) suggest a physiological basis for their existence. $\mathrm{LDH}-4$ and LDH-5 which contain mainly $M$ subunits permit rapid accumulation of lactate, and are found in skeletal muscle where anaerobic glycolysis predominates, whereas $\mathrm{LDH}-1$ and $\mathrm{LDH}-2$ containing mainly $\mathrm{H}$ subunits are found in heart, where pyruvate is oxidized via the Krebs cycle (Basaglia, 1989). Very little information is available on LDH from reptiles. In our previous studies (Javed et al., 1995), we have shown that LDH from a reptile, Uromastix hardwickii, has four isoenzymes in the liver which differ in physicochemical and electrophoretic properties from livers of other animals. Similarly, the characteristics of LDH isoenzyme purified from testes of $U$. hardwickii are also different from other animals (Javed et al., 1994; Javed and Waqar, 1996). In this paper, we have described the properties of purified LDH from liver of another reptile, Varanus bengalensis.

\section{Materials and Methods}

\section{Materials}

Fresh livers were obtained from Varanus bengalensis and frozen at $-20^{\circ} \mathrm{C}$ until use. No distinctions were made between male and female animals. NADH, NAD ${ }^{+}$, agarose, lithium lactate, nitroblue tetrazolium (NBT), phenazine methosulfate (PMS), agarose type-1 low EEO, MW SDS-200 kit and sodium pyruvate were from Sigma Chemical Co., U.S.A. 1,6-Hexanediol (extra pure) was from Aldrich Chemical Co. Inc., U.S.A. Colchicine- $\mathrm{CH}-S e p h a r o s e$ was a gift from Dr. Tomoji Kocha (Department of Hygienic Chemistry, Showa College of Pharmaceutical Sciences, Tokyo, Japan). All other chemicals were of analytical grade.

\section{Purification of LDH}

All purification procedures of LDH were performed at 0$4^{\circ} \mathrm{C}$, otherwise indicated. Frozen liver was thawed and the LDH was purified to homogeneity by ammonium sulphate fractionation and colchicine-sepharose column 
chromatography according to the methods previously described (Javed et al. 1995).

\section{Gel electrophoresis}

To resolve the types of LDH isoenzymes in liver extract and chromatographic fractions, we used horizontal agarose gel electrophoresis. One percent ultrathin $(0.4$ $\mathrm{mm})$ horizontal agarose gel $(7.5 \times 10 \mathrm{~cm})$ was prepared on gel bond and electrophoresis and LDH staining were carried out as described elsewhere (Javed et al., 1995). To check the purity of the LDH, SDS-PAGE was done according to the method described by Gorg et al. (1985) using a gradient gel from $7.5 \%$ to $25 \%$.

\section{Molecular mass determination}

The molecular mass of the LDH was estimated using a $1.5 \times 73 \mathrm{~cm}$ column packed with approximately $125 \mathrm{ml}$ of Sepharose CL-6B in phosphate buffer containing EGTA (KPE) buffer. All standard proteins and dextran blue were passed through column separately.

\section{Enzyme and protein assays}

Enzyme activity was measured in the forward reaction $\left(\mathrm{NADH}\right.$ to $\mathrm{NAD}^{+}$) at $25^{\circ} \mathrm{C}$ in a reaction mixture containing $50 \mathrm{mM}$ phosphate buffer ( $\mathrm{pH}$ 7.5), $0.18 \mathrm{mM} \mathrm{NADH}, 0.6$ $\mathrm{mM}$ sodium pyruvate and a suitable amount of enzyme to obtain a measurable decrease in absorbance at 340 $\mathrm{nm}$ using Beckman DU70 UV-Vis spectrophotometer. One unit of enzyme was defined as the amount of

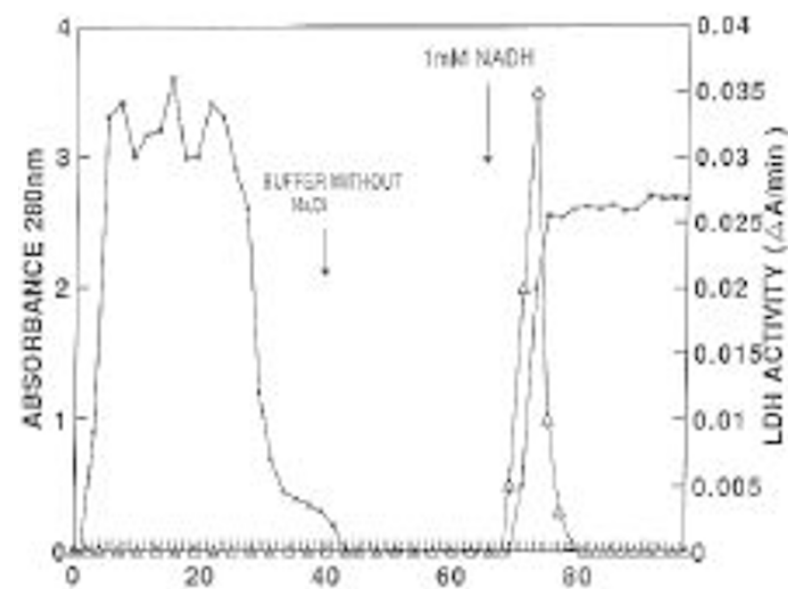

Figure1. Colchicine-Sepharose column chromatography of LDH from Varanus liver. Sample was loaded onto a column $(1.5 \times 2 \mathrm{~cm})$ of immobilized colchicine-Sepharose equilibrated with $2.5 \mathrm{M} \mathrm{NaCl}-\mathrm{KPE}$ buffer. The column was washed with the same buffer. To wash out glyceraldehyde 3-phosphate dehydrogenase, $\mathrm{KPE}$ buffer without $\mathrm{NaCl}$ was passed through the column. LDH was then eluted with $1 \mathrm{mM} \mathrm{NADH}$ in KPE buffer. The flow rate was about $40 \mathrm{ml} / \mathrm{h}$ and $1 \mathrm{ml}$ fractions were collected. The protein concentration $(\square)$ was measured as $A_{280}$. The enzyme activity ( $\boldsymbol{\Delta}$ ) was determined by measuring the change in absorbance at $340 \mathrm{~nm}$ min- 1 at $25^{\circ} \mathrm{C}$. enzyme that produced one micromol of $\mathrm{NAD}^{+}$per min under the assay conditions. A molar absorption coefficient for $\mathrm{NADH}$ of $6.22 \times 10^{3} \mathrm{M}^{-1} \mathrm{~cm}^{-1}$ at $340 \mathrm{~nm}$ was used for calculations (Voorter et al., 1993). For the reverse reaction $\left(\mathrm{NAD}^{+}\right.$to $\left.\mathrm{NADH}\right)$, the enzyme activity was determined by measuring an increase in absorbance at $340 \mathrm{~nm}$. The final concentration of the reactants in a standard reaction mixture was $50 \mathrm{mM}$ Tris- $\mathrm{HCl}$ buffer (pH 9.5), $50 \mathrm{mM}$ lithium lactate and $0.1 \mathrm{mM} \mathrm{NAD}^{+}$. It contained $20 \mu \mathrm{l}$ of suitably diluted enzyme. The volume of reaction mixtures in both cases was $1 \mathrm{ml}$. $K_{\mathrm{m}}$ and $V_{\max }\left(K_{\text {cat }}\right)$ values were calculated from initial velocity measurements, using Enzfitter (R. J. Leather-barrow), a non-linear regression program that integrates the data into the Michaelis-Menton equation, with simple weighting. Proteins were determined by the method of Lowry et al. (1951) with bovine serum albumin as standard.

For inhibition studies, a known concentration of the test modulator (after adjusting $\mathrm{pH} 7.5$ for forward reaction and $\mathrm{pH} 9.5$ for reverse reaction) was added to the reaction mixture. The activity of the enzyme was then measured by the forward or reverse reactions. The results are expressed as remaining activity (in \%) compared to control $(100 \%)$. The effect of these chemicals were also observed on the oxidation/reduction of $\mathrm{NADH} / \mathrm{NAD}^{+}$in the absence of enzyme. The nature of oxalate inhibition was determined using Lineweaver-Burk plots.

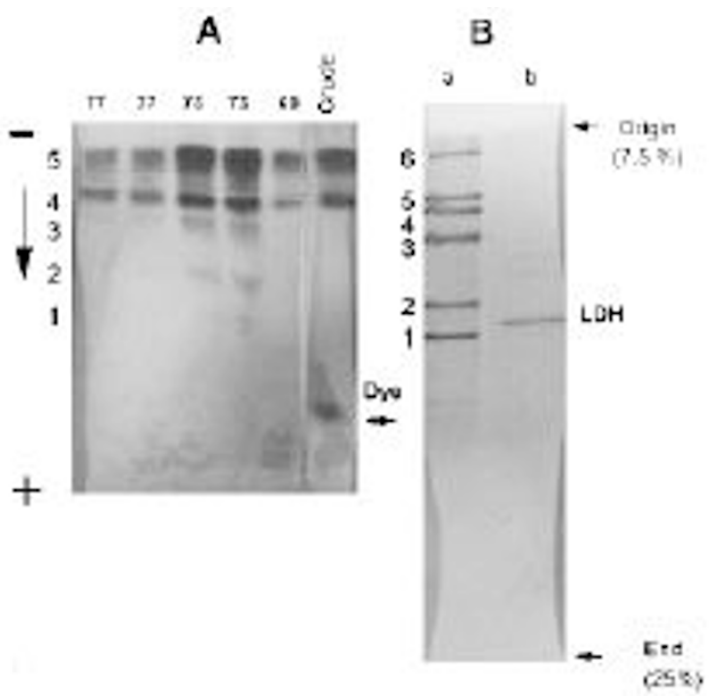

Figure 2. A. Agarose gel electrophoresis (AGE) of LDH from Varanus liver. Lanes 69 73 and 77 are tube number after elution of LDH from colchicine-Sepharose column by $\mathrm{NADH}$. Crude sample is liver extract. B. SDS-PAGE of purified LDH. a, reference proteins are; 1 , carbonic anhydrase (29 kDa); 2, egg albumin (45 kDa); 3, BSA (66 $\mathrm{kDa}) ; 4$, phosphorylase B (97.4 kDa); 5 , $\beta$-galactosidase (116 kDa); 6 , myosin (205 $\mathrm{kDa})$; b, purified LDH. 


\section{Results}

\section{Colchicine-Sepharose chromatography}

When dialyzed liver extract was applied on a colchicinesepharose column, the entire LDH activity was retained by the column. Addition of $1 \mathrm{mM} \mathrm{NADH}$ in KPE buffer eluted LDH in a sharp peak (Figure 1). The agarose gel electrophoresis (AGE) of LDH is shown in Figure 2. Two bands of $\mathrm{LDH}$ (LDH4 and 5) were identified in $40-80 \%$ ammonium sulphate fraction, while five LDH isoenzymes were resolved in peak fraction (Number 73) after colchicine-Sepharose column chromatography. The major isoenzyme in all cases was LDH-5 (about 70\%). The purity of LDH was checked by SDS-PAGE which showed a single band corresponding to the molecular mass of about $35 \mathrm{kDa}$ (Figure $2 \mathrm{~B}$, lane b). The molecular mass of native LDH was calculated to be about $140 \mathrm{kDa}$ (Table 1) by Sepharose column chromatography.

Table 1. Elution volumes from Sepharose CL-6B column

\begin{tabular}{lcc}
\hline Sample & Mol.Wt. (KDa) & Elution volume $(\mathrm{ml})$ \\
\hline Blue dextran & 2000 & 42.5 \\
Thyroglobulin & 669 & 64.0 \\
LDH & $140^{\mathrm{a}}$ & 79.0 \\
BSA & 67 & 85.5 \\
Cytochrome c & 12 & 96.5 \\
\hline
\end{tabular}

a calculated

Table 2. Purification of LDH from Varanus liver

\begin{tabular}{lccc}
\hline Step & $\begin{array}{c}\text { Protein } \\
(\mathrm{mg} / \mathrm{ml})\end{array}$ & $\begin{array}{c}\text { Activity } \\
(\mathrm{U} / \mathrm{ml})\end{array}$ & $\begin{array}{c}\text { Specific Activity } \\
(\mathrm{U} / \mathrm{mg})\end{array}$ \\
\hline Crude Extract & 12.2 & 83.0 & 6.8 \\
$\begin{array}{l}40-80 \%\left(\mathrm{NH}_{4}\right)_{2} \mathrm{SO}_{4} \\
\text { Fraction }\end{array}$ & 2.77 & 18.5 & 6.7 \\
$\begin{array}{l}\text { Colchicine-Sepharose } \\
\text { Chromatography }\end{array}$ & 0.055 & 8.0 & 145.45 \\
\hline
\end{tabular}

Table 3. Kinetic parameters of LDH. The assay of enzyme was performed as described in the Materials and Methods at $25^{\circ} \mathrm{C}$. The amount of enzyme was adjusted so as to give a change in absorption from 0.05 to $0.06 \mathrm{~min}^{-1}$.

\begin{tabular}{lcc}
\hline Variable substrate & $K_{\mathrm{m}}(\mathrm{mM})$ & $V_{\max }\left(\mu \mathrm{mol} \mathrm{min} \mathrm{ml}^{-1}\right)$ \\
\hline Pyruvate & $0.17 \pm 0.037$ & $0.56 \pm 0.05$ \\
$\mathrm{NADH}$ & $0.02 \pm 0.004$ & $0.33 \pm 0.02$ \\
Lactate & $12.4 \pm 3.05$ & $0.27 \pm 0.036$ \\
$\mathrm{NAD}^{+}$ & $0.38 \pm 0.032$ & $0.165 \pm 0.005$
\end{tabular}

The results from a representative purification according to the procedure described in the "Materials and Methods" section are shown in Table 2. The specific activity of purified LDH was $145.45 \mathrm{U} / \mathrm{mg}$ protein. The purified enzyme was stable at $4^{\circ} \mathrm{C}$ for at least 2 years while it was unstable at room temperature.

\section{Kinetic studies}

The $\mathrm{pH}$ profiles of LDH for the forward and reverse directions are shown in Figure 3. In the forward direction the optimum $\mathrm{pH}$ was 7.0. For the reverse reaction, the enzyme showed an optimum $\mathrm{pH}$ at 9.5 . The activity was still very high (about 55\%) even at $\mathrm{pH} 11.0$.

Table 3 summarizes the results of experiments in which kinetic parameters of $\mathrm{LDH}$ for pyruvate, lactate, $\mathrm{NADH}$ and $\mathrm{NAD}^{+}$. Before analyzing the effects of the concentrations of various substrates, $\mathrm{LDH}$ was dialyzed against KPE for overnight to remove NADH. With pyruvate as the variable substrate, the apparent $K_{\mathrm{m}}$ was about $170 \pm 37 \mu \mathrm{M}$ while the $V_{\max }$ was $0.56 \pm 0.05$ $\mu \mathrm{mol} / \mathrm{min}$. Similarly, the $K_{\mathrm{m}}$ and $V_{\max }$ for NADH were 20 $\pm 4 \mu \mathrm{M}$ and $0.33 \pm 0.02 \mu \mathrm{mol} / \mathrm{min}$, respectively. The $K_{m}$ values for $\mathrm{NAD}^{+}$and lactate were $0.38 \pm 0.032 \mu \mathrm{M}$ and $12.4 \pm 3.05 \mathrm{mM}$, while $V_{\max }$ values were $0.165 \pm 0.005$ $\mu \mathrm{mol} / \mathrm{min}$ and $0.27 \pm 0.036 \mu \mathrm{mol} / \mathrm{min}$, respectively.

\section{Heat stability studies}

Purified LDH was incubated at a concentration of about $0.4 \mathrm{U} / \mathrm{ml}$ in water bath at given temperature for $5 \mathrm{~min}$ as shown in Figure 4. The enzyme was then cooled in ice and the residual activity was measured. Figure 4 shows the heat-inactivation profile of LDH for the forward and the reverse reactions. The $t_{50}$ values (the temperature

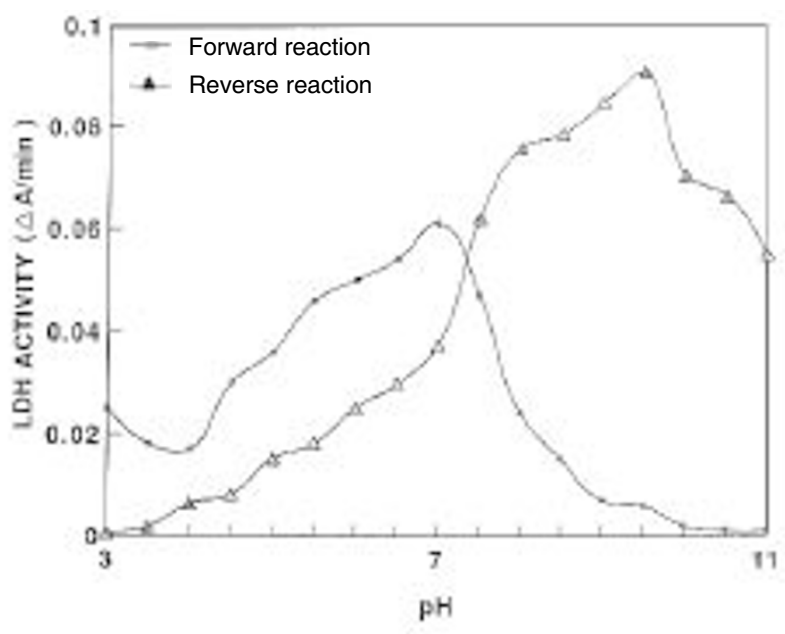

Figure 3. Effect of varying pH on activity of LDH from Varanus liver. The composition of reaction mixture was same as explained in the 'Materials and Methods'. 


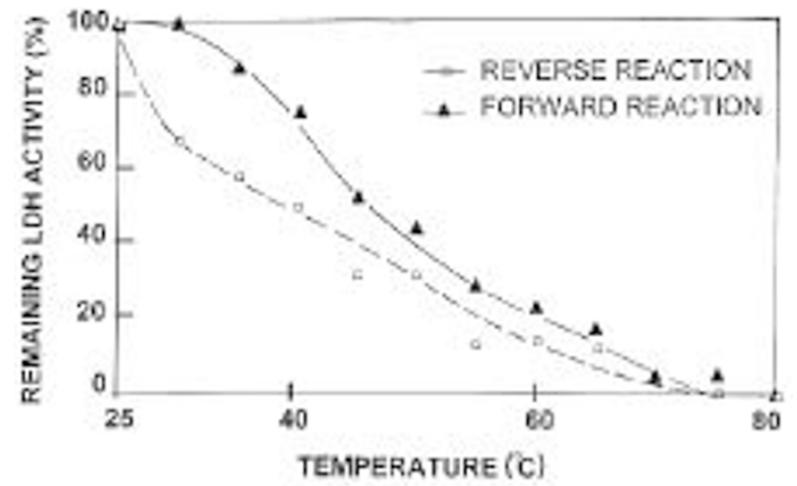

Figure 4. Effect of pre-heating upon activity of LDH. The purified LDH was incubated for 5 min at various temperatures. An aliquot was then taken and kept in ice. After completing the experiment, the activity of LDH was measured both for forward and reverse reactions as explained in the 'Materials and Methods'.

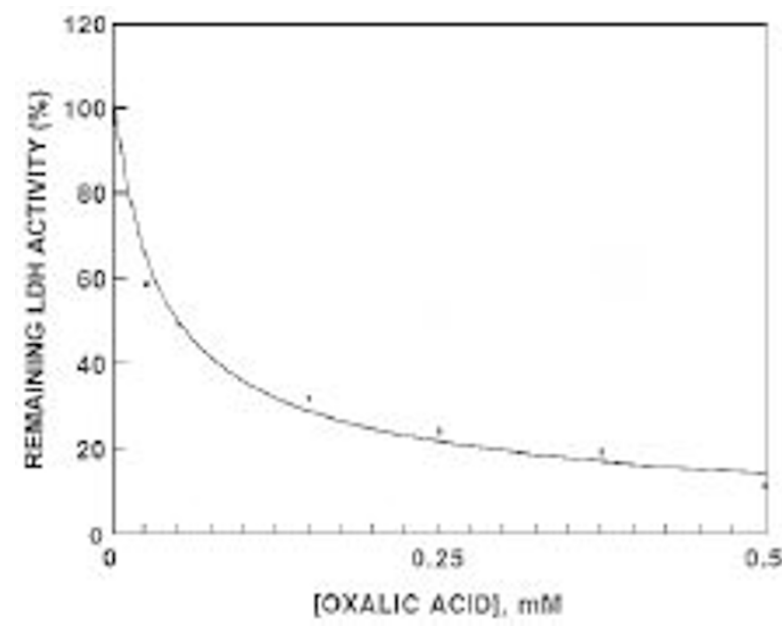

Figure 5. Effect of oxalate on inhibition of LDH. An indicated amount of oxalate was added in the reaction mixture, and then the activity of LDH was determined as described for the forward reaction in the 'Materials and Methods'.

at which $50 \%$ of the activity remains after an incubation of $5 \mathrm{~min}$ ) for forward-reaction is about $50^{\circ} \mathrm{C}$ and for reverse-reaction, it is $40^{\circ} \mathrm{C}$.

\section{Effect of Inhibitors}

The effect of various modulators on the LDH activity is shown in Table 4. Oxalate was found to be a strong inhibitor, both for the forward and reverse directions particularly at $1 \mathrm{mM}$ concentrations. The apparent $\mathrm{IC}_{50}$ (concentration where $50 \%$ inhibition was observed) was found to be about $0.05 \mathrm{mM}$ (Figure 5). Glutamate was a more effective inhibitor in the reverse reaction $(100 \%$ inhibition) as compared to the forward reaction $(22.3 \%$ inhibition) at $20 \mathrm{mM}$ concentration. $\mathrm{Cu}^{++}$and $\mathrm{Co}^{++}$were
Table 4. Effect of inhibitors on LDH activity

\begin{tabular}{|c|c|c|c|}
\hline \multirow{2}{*}{ Inhibitors } & \multirow{2}{*}{ Concentration (mM) } & \multicolumn{2}{|c|}{ Remaining activity ${ }^{\mathrm{a}}(\%)$} \\
\hline & & $\begin{array}{l}\text { Forward } \\
\text { reaction }\end{array}$ & $\begin{array}{l}\text { Reverse } \\
\text { reaction }\end{array}$ \\
\hline Control & 0.0 & 100.0 & 100.0 \\
\hline \multirow[t]{2}{*}{ Oxalate } & 0.5 & 19.0 & 98.0 \\
\hline & 1.0 & 7.5 & 35.0 \\
\hline \multirow[t]{2}{*}{ Glutamate } & 10.0 & 89.0 & 5.0 \\
\hline & 20.0 & 77.7 & 0.0 \\
\hline \multirow[t]{2}{*}{$\mathrm{Cu}^{2+}$} & 0.5 & 59.0 & 80.0 \\
\hline & 1.0 & 23.8 & 70.0 \\
\hline \multirow[t]{2}{*}{$\mathrm{Co}^{2+}$} & 0.5 & 95.0 & 100.0 \\
\hline & 1.0 & 0.0 & 100.0 \\
\hline \multirow[t]{2}{*}{$\mathrm{Mn}^{2+}$} & 0.5 & 100.0 & 100.0 \\
\hline & 1.0 & 84.0 & 100.0 \\
\hline \multirow[t]{2}{*}{$\mathrm{Mg}^{2+}$} & 0.5 & 99.9 & 100.0 \\
\hline & 1.0 & 88.8 & 90.0 \\
\hline \multirow[t]{2}{*}{ n-Hexanediol } & 400.0 & 81.5 & 75.0 \\
\hline & 800.0 & 68.5 & 55.0 \\
\hline
\end{tabular}

${ }^{a} \mathrm{~A}$ known amount of modulator was added in the reaction mixture and then the activity of LDH was determined as explained in the 'Materials and Methods'. Values are mean for three determinations for all except for $n$-hexanediol which were repeated for four times.

more effective inhibitors for forward reactions as compared to the reverse reactions. $\mathrm{Mn}^{2+}$ and $\mathrm{Mg}^{2+}$ had almost no effect on LDH activity on either sides of reaction. $n$-Hexanediol has also shown inhibition for forward and reverse reactions with $\mathrm{IC}_{50}$ of about $1.5 \mathrm{M}$ and $0.75 \mathrm{M}$, respectively (Figure 6).

\section{Discussion}

Lactate dehydrogenase from various mammalian species have been shown to be made up of five isoenzymes. We have observed that LDH from skeletal muscles of a reptile, Uromastix hardwickii consisted of six isoenzymes and they can not be separated by usual methods of electrophoresis (Javed et al., 1992). The purified LDH isoenzymes from liver and testes of Uromastix were quite different from other species (Javed et al., 1994; Javed et al., 1995). Considering the results of Uromastix $\mathrm{LDH}$, we have decided to study the properties of LDH purified from another reptile, Varanus. It has been well established that the liver of rat, and man contains two $\mathrm{LDH}$ isoenzymes (LDH-5 and LDH-4) with $98 \%$ as LDH5 , i.e., M-type. The rabbit liver showed three isoenzymes (LDH-5, LDH-4 and LDH-3) with LDH-5 as predominant isoenzymes (Maly and Toranelli, 1993). The cattle liver showed three isoenzymes (LDH-4, LDH-3 and LDH-2) while pig liver showed four isoenzymes (LDH-4, LDH-3, 


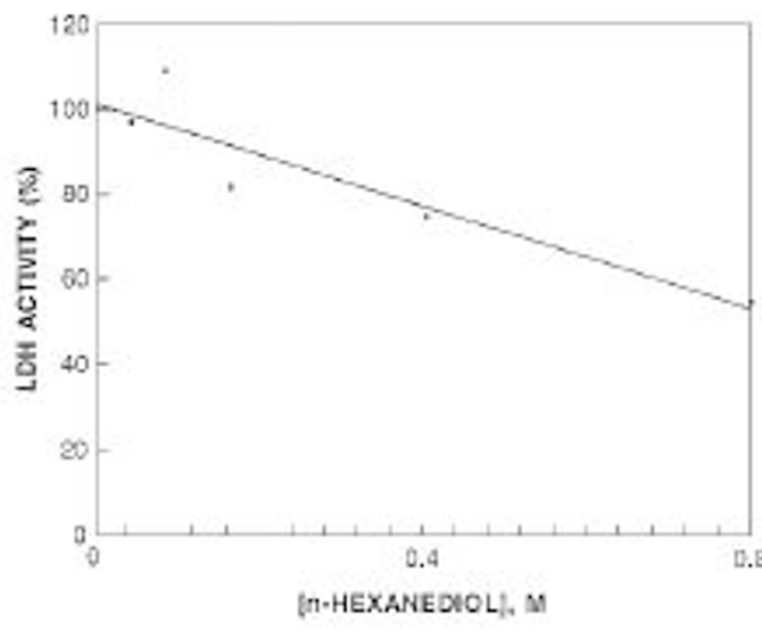

Figure 6. Effect of $n$-hexanediol on the inhibition of LDH. A known amount of $n$ hexanediol was added in the reaction mixture, and the LDH activity was determined for forward and reverse reactions as explained in the 'Materials and Methods'.

LDH-2 and LDH-1) with LDH-3 and LDH-2 as predominant isoenzymes (Maly and Toranelli, 1993). Varanus liver showed two isoenzymes (LDH-5 and LDH-4) same as in human liver. The $K_{\mathrm{m}}$ values for pyruvate, $\mathrm{NADH}$ and $\mathrm{NAD}^{+}$were quite different in compared to Uromastix liver $\mathrm{LDH}$ which are about $15 \mu \mathrm{M}, 40 \mu \mathrm{M}$ and $10 \mu \mathrm{M}$, respectively (Javed et al. 1995). The reason is probably the type of LDH isoenzyme. We purified LDH-1 from uromastix liver previously (Javed et al., 1995). It has been known that the kinetic properties of LDH-1 and LDH-5 are quite different (Everse and Kaplan, 1973; Maekawa, 1988). However, the $K_{m}$ for lactate in Varanus LDH was almost similar to LDH from Uromastix (Javed et al., 1995). One of the main functions of liver is to convert lactate into pyruvate for energy or gluconeogenesis (Stryer, 1995). The $\mathrm{pH}$ and temperature effects on Varanus LDH were almost similar to LDH-5 from other sources (Hayashi et al. 1985; Javed, et al. 1995). The molecular weight of native LDH (140 kDa) from Varanus liver was same as previously reported. (Everse and Kaplan, 1973; Maekawa, 1988) and that of subunits was found to be about $35 \mathrm{kDa}$. Thus the Varanus liver $\mathrm{LDH}$ is also made up of four subunits.

The inhibition of this LDH by oxalate is in accordance with previous reports (Everse and Kaplan, 1973). In most of the cases, oxalate has been shown to be either competitive or non-competitive types of inhibitor (Saxena et al., 1986; Javed and Waqar, 1993). Glutamate has been shown to protect the inactivation of LDH from the skeletal muscles of Carp (Nakajima et al., 1993). In Varanus liver LDH it was strong inhibitor for the reverse-direction only. We had also observed less inhibition by glutamate in case of LDH from Uromastix liver for the forwardreaction (Javed et al., 1995). $\mathrm{Cu}^{2+}$ and $\mathrm{Co}^{2+}$ inhibition was more evident for forward reaction as compared to reverse-reaction while $\mathrm{Mn}^{2+}$ and $\mathrm{Mg}^{2+}$ were least effective which were shown to inhibitors of LDH from some other sources (Yoshido, 1965; Saxena, 1986; Javed et al., 1995). However, $\mathrm{CO}^{2+}, \mathrm{Mg}^{2+}$ and $\mathrm{Mn}^{2+}$ have been shown to be activators of LDH from Norcadia asteroides (lke et al., 1992). The reason may be that LDH from $N$. asteroides was shown to be a membrane-bound enzyme, while we have purified the LDH from the cytosol of liver. $n$-Hexanediol has been shown to be a non-competitive inhibitor for human LDH-5 with pyruvate as substrate (Tanishima et al., 1985).

From electrophoretic and other biochemical properties, it seems that the LDH of Varanus liver resembles mostly human liver LDH and quite different from the liver LDH of Uromastix, another reptile (Javed et al., 1995).

\section{Acknowledgements}

The authors gratefully acknowledge Mrs. Seema Tariq Khan and Mr. Jack Fernandes for secretarial and transcription assistance.

\section{References}

Basaglia, F. (1989) Some aspects of isoenzymes of LDH, MDH and glucose-phosphate isomerase in fish. Comp. Biochem. Physiol. 92B: 213-226

Cahn, R. D., Kaplan, N. O., Levine, L. and Zwilling, E. (1962) Nature and development of LDH. Science 136: 962-969

Everse, J. and Kaplan, N. O. (1973) Lactate dehydrogenase: structure and function. Adv. Enzymol. 37: 61-131

Gorg, A., Postel, W., Weser, J., Schiwara, H. W. and Boesken, W. H. (1985) Horizontal SDS electrophoresis in ultrathin pore-gradient gels for the analysis of urinary proteins. Sci. Tools 32: 5-9

Hayashi, S., Ooshiro, Z., Itakura, T. and Masuda, Y. (1985) Biochemical properties of LDH purified from the eel liver. Bull. Japan. Soc. Sci. Fisheries 51: 79-85

Ike, J., Sangam, P. and Gunawekaran, M. (1992) Purification and properties of LDH from Norcardia asteroides. Microbios. 69: 119-127

Javed, M. H., Hussain, A. N. and Waqar, M. A. (1992) Heat-stabilizing factor of LDH in the skeletal muscle of uromastix. Biochem. Soc. Trans. 20: 208S

Javed, M. H. and Waqar, M. A. (1993) Properties of LDH isoenzyme-1 from goat brain Korean J. Biochem. 25: 49-54

Javed, M. H., Qureshi, M. A. and Waqar, M. A. (1994) The isoenzyme forms of LDH form the testes of Uromastix hardwickii. Biochem. Mol. Biol. Int. 34: 963-970

Javed, M. H., Yousuf, F. A., Hussain, A. N., Ishaq, M. and Waqar, M. A. (1995) Purification and properties of LDH from liver of Uromastix hardwickii. Comp. Biochem. Physiol. 111B: 27-34

Javed, M. H. and Waqar, M. A. (1996) Inhibition studies on LDH isoenzyme purified from Uromastix testes. J. Enz. Inhibition 10: 187-193

Li, S., O'Brien, D.A., Hou, E. W., Versala, J., Rockett, D. L. and Eddy, E. M. (1989) 
Differential activity and synthesis of LDH isoenzyme A (muscle), B (heart) and C (testis) in mouse spermatogenic cells. Biol. Reprod. 40: 173-180

Lowry, O. H., Rosenbrough, N. J., Farr, A. L. and Randall, R. (1951) Protein measurement with folin phenol reagent. J. Biol. Chem. 193: 265-275

Maekawa, M. (1988) Lactate dehydrogenase isoenzyme. J. Chromatogr. 429: 373-398

Nakajima, S., Tamiya, T., Akahame, T. and Matsumoto, J. J. (1993) Prevention of inactivation of LDH of carp muscle during extraction, purification and dilution. Bull. Japan. Soc. Sci. Fisheries 49: 265-271

Saxena, N., Pandey, V. C., Dutta, G. P. and Ghatak, S. (1986) Charac-terization of LDH of Plasmodium knowlesi. Mol. Biochem. Parasitol. 21: 199-202

Stryer, L. (1995) In Biochemistry 4th ed., pp. 763-784, W. H. Freeman and Co., New York

Tanishima, K., Hayashi, T., Matsushima, M. and Mochikawa, Y. (1985) Activity of LDH isoenzymes LD1 and LD2 in serum as determined by using an inhibitor of the Msubunit. Clin. Chem. 31: 1175-1177

Voorter, C. E. M., Wintjes, L. T. M., Heinstra, P. W. H., Bloemendal, H. and deJang, W. W. (1993) Comparison of stability properties of $L D H-B_{4} /$-crystallin from different species. Eur. J. Biochem. 211: 643-648

Yoshido, A. (1965) Enzymatic properties of LDH of Bacillus subtilis. Biochim. Biophys. Acta 99: 66-67 